\title{
"Brasilhana": la creación de un signo musical transcultural
}

\author{
Maria Elizabeth Lucas
}

Este artículo trata un caso específico de regionalismo musical dentro de las múltiples expresiones contemporáneas de la música popular brasileña; a saber, el repertorio de canciones de música gaucho/nativista producidas en el flujo de un movimiento de revitalización que nació en la década de 1970 en el sur de Brasil. Partiendo de un análisis musicobiográfico de una canción específica, el texto presenta el carácter contextual de los signos musicales empleados como marcadores de identidad transnacional/nacional/regional, la agencia de los creadores de música en la construcción de identidad social y la cuestión del esencialismo en los sistemas de clasificación musical, sobre todo respecto a temas de tradición/autenticidad.

This article focuses on a specific case of music regionalism within the multiple contemporary idioms of Brazilian popular music, namely the song repertoire of Gaucho/Nativist music, which has been produced in the stream of a revivalist movement in southern Brazil born in the 1970s. Departing from a music-biographic analysis of a specific song, the text brings forward the contextual character of music signs used as transnational/national/regional identity markers, the agency of music creators in social identity construction and the question of essentialism in music classificatory systems, especially in relation to matters of tradition/authenticity.

Maria elizabeth lucas: Universidade do Río Grande do Sul, Brasil.

Desacatos, núm. 12, otoño 2003, pp. 62-77.

- Traducción de Isabel Marmasse. 


\section{INTRODUCCIÓN}

$\mathrm{E}$ ste artículo trata sobre un caso específico de regionalismo musical dentro de las múltiples expresiones contemporáneas de la música popular brasileña; a saber, el repertorio de canciones de Río Grande do Sul (RS) —el estado sureño de Brasil—, conocido como música nativista gaucha. Dada su condición fronteriza, en las zonas que colindan con Argentina y Uruguay, la sociedad del sur de Brasil se ha representado históricamente en el Estado nación como siendo más hispano-europea que luso-africana-brasileña. Considerada una de las mejores áreas del país en términos de desarrollo social y económico, el atractivo de una herencia europea — debido a las olas de inmigración alemana e italiana durante el siglo XIX — llena la imaginación local con el orgullo de una descendencia de un linaje "más alto". ${ }^{1}$ Éstas y otras representaciones sociales, que se presentarán más adelante, han permeado una amplia gama de discursos locales, incluyendo la música popular. La orientación epistemológica adoptada aquí, siguiendo los cánones de la investigación etnográfica, busca ubicar las representaciones y agencias sociales en el discurso musical dentro de la dinámica de la interacción social, es decir, en el tiempo y el espacio en los cuales los agentes sociales construyen, reproducen y transforman la cultura. Partiendo de un análisis musicobiográfico de una canción nativista llamada "Brasilhana" (brasileña + castellana) quiero señalar los siguientes puntos: a) el carácter contextual de los signos musicales utilizados como marcadores de identidad nacional/regional; b) la agencia de los creadores de música (definida como estrategias desplegadas para controlar el uso del capital musical en un contexto dado) en la construcción de identidad social y,

\footnotetext{
${ }^{1}$ De acuerdo con el censo nacional de 2000, la población de Río Grande do Sul es de alrededor de diez millones de habitantes. El 30\% vive en las áreas rurales y el $70 \%$ en las urbanas. La capital del estado, Porto Alegre, tiene aproximadamente millón y medio de habitantes. A pesar del incremento en los índices de pobreza en Brasil, la sociedad de Río Grande do Sul aún mantiene una de las mejores tasas de distribución de ingresos y cuenta con una numerosa clase media. Estas cifras económicas también ayudan a explicar la expansión en las últimas décadas de una industria cultural local basada en el mercadeo de productos y tradiciones regionales (música, bailes, artesanía, gastronomía).
}

en este caso específico, en los procesos transculturales; y c) el problema del esencialismo en los sistemas de clasificación musical, sobre todo respecto a cuestiones de tradición y autenticidad.

\section{ACERCA DE CANCIONES, EJECUCIÓN MUSICALY SU CONTEXTO}

El énfasis que pongo en la etnografía de una canción específica requiere un resumen de las cuestiones principales incluidas en tal perspectiva de análisis. La canción es una unidad emocionalmente poderosa por su propio derecho. Es una intersección entre dos sistemas de comunicación distintos —el lenguaje y la música-. A pesar de ello, las canciones no pueden reducirse a estos dos códigos por sí solos, puesto que se complementan plenamente al activarse simultáneamente en la ejecución. En el caso de los recientes estudios de la canción popular con enfoque musical, se detecta un claro interés de la parte de los autores en llenar el vacío entre los procesos/estructuras sociales y musicales. Existen tesis de ese tipo en los modelos teóricos que se basan en la teoría cultural marxista (p. ej. Shepherd, 1982, 1991; Hennion, 1983; Pickering, 1987; Middleton, 1990), los estudios culturales y los estudios de recepción (Brackett, 1997) y/o una elección entre la semiótica de Saussure, Peirce, Greimasi (p. ej. Tagg, 1982; Giroux, 1985; Tatit, 1986, 1994, 1995). A pesar de seguir algunas de las sugerencias analíticas planteadas en dichos estudios, en este artículo me enfocaré sobre todo en la etnografía de las presentaciones de la canción misma como una herramienta de metodología para llegar al meollo de los significados culturales englobados en la producción-recepción de un artefacto musical específico.

Las complejidades que conlleva el proceso de la significación musical, especialmente como lo señalan aquellos etnomusicólogos que conciben la música como un proceso comunicativo, les han proporcionado elementos para replantear las limitaciones de los estudios musicales que se centran en el código per se (p. ej. Blacking, 1983; Feld, 1984). Como señala Feld, el proceso de significado musical depende de la interacción dialéctica entre 
el "productor de código" y el "consumidor de mensaje”. Los análisis que no toman en cuenta este hecho sólo pueden ofrecer una visión parcial del proceso de comunicación. En el caso de las canciones, dicha interacción dialéctica está limitada al contexto en el cual se entrecruza la cadena productor-código-receptor. Por consiguiente, la ejecución misma y el marco musical en el cual se introducen las canciones deben integrarse en el análisis puesto que conforman la situación contextual inmediata en el que se interpreta el significado de la canción.

Para resumir mi argumento, aquí las canciones se conciben como un sistema semiótico que se construye social y culturalmente. Por ende, el análisis de los vehículos de los signos en las canciones toma en cuenta la relación entre los dispositivos de sonido/texto/ejecución y el contexto específico en el cual las canciones se vuelven significativas para la audiencia en su calidad de miembros de un grupo sociocultural, un argumento que destaca la cuestión de la ejecución en vivo.

El musicólogo/semiólogo italiano Gino Stefani observa que una idea que se expresa por medio de más de un sentido (vista, oído, tacto) deja una huella más fuerte en el receptor, puesto que implica varios niveles de asociación (1987: 30). El resultado es la polisensorialidad, un proceso de comunicación que surge del entrecruzamiento de varios medios de expresión como es el caso de las presentaciones musicales en vivo. Por ende, las canciones interpretadas en vivo tienden a intensificar su poder comunicativo.

Como dice Bauman en sus estudios dedicados a los eventos de representación (p. ej. 1977, 1991), la ejecución es un modo de comunicación que se manifiesta en la manera particular que liga al público y a los intérpretes. La afinidad directa entre los miembros del público y los intérpretes en las presentaciones en vivo crea un vínculo especial entre la situación de escuchar y el espacio/evento, "resaltando la manera en la cual se lleva a cabo la comunicación, más allá del contenido referencial” (1991: 3). Las canciones presentadas pueden captar la atención de los participantes mediante la letra, los gestos, la entonación vocal, los efectos de sonido, el timbre, además de su nivel de involucramiento ideológico y emocional con los intérpretes, compositores y el mismo evento. Estos estí- mulos variados y complejos actúan en los participantes de distintas maneras para despertar su respuesta, que se externa en su conducta verbal y no verbal. Éste es el caso observado en el marco de la representación de la canción que se estudia aquí.

La versión actual del renacimiento gaucho ${ }^{2}$ en el sur de Brasil se apoya mucho en el modelo de festivales/concursos de canciones para que los músicos, los autores y los compositores locales exhiban su conocimiento de temas relacionados con la cultura regional (géneros musicales locales, historia, folclor, poesía oral, etc.). Para el público en general el gran atractivo del festival nativista radica en la conducta social festiva y la interacción por vía lúdica: la posibilidad y los medios que tienen los participantes para desconcertar, fascinar, llamar la atención o afirmar una identidad gaucha. En los términos de Victor Turner, éstas son representaciones culturales liminoides (1982: 43,53): formas rituales de esparcimiento en las sociedades industriales para las cuales hay que pagar una entrada, y la participación es un acto voluntario más que un ritual obligatorio como sucede en las sociedades precapitalistas. Durante el concurso, dicho ánimo festivo está controlado por una variedad de recursos: la cercanía visual-auditiva de los participantes, el movimiento fuera y dentro del escenario de los músicos vestidos con el atuendo gaucho, la expectativa creada por el concurso y el involucramiento físico del público. Toda una gama de actividades físicas acompañan a las canciones interpretadas en el escenario. Dado que muchas canciones se basan en géneros bailables (véase abajo), también permiten el coqueteo y el baile. Si bien los individuos son libres de expresar sus sentimientos, éstos suelen ser homogeneizados por las convenciones en las cuales se enmarca el evento: cantar, gritar, abuchear, aplaudir, exhibir banderolas, manifestar las camarillas, que representan un aspecto esencial del papel de participación del público en la representación.

\footnotetext{
${ }^{2}$ La palabra "gaucho/a" designa hoy en día al trabajador (peón) campesino rural de los ranchos así como a cualquier persona nacida en Río Grande do Sul. En este texto lo capitalizo para designar el concepto de una cultura e identidad regionales basadas en las tradiciones y valores asociados con la historia local, el pastoreo de la pampa y la figura mítica del gaucho peón.
} 
Dichas consideraciones establecen el marco teórico del análisis de la canción "Brasilhana" que tratamos a continuación. Como recomienda Bauman, "la primera tarea en el estudio de los eventos de representación es identificar a los eventos en sí de manera consistente con las interpretaciones locales y relevante con los problemas analíticos inmediatos" (idem). A continuación se introduce una pieza etnográfica sobre el festival/concurso de canción Musicanto, celebrado en 1986, en el cual "Brasilhana" fue la canción ganadora.

\section{EL MARCO DEL CONCURSO: EL CUARTO MUSICANTO SUL AMERICANO DE NATIVISMO}

En la década de 1970, el regionalismo gaucho experimentó un proceso de revitalización en Río Grande do Sul. En pocas palabras, este movimiento renovador se cimienta en las expresiones sociales y simbólicas creadas alrededor de lo pastoril y la cultura del gaucho vaquero de las planicies sudamericanas. Como una construcción ideológica, que se repite más determinantemente en algunas ocasiones que en otras, ${ }^{3}$ la versión presente de la gauchería surgió mediante festivales (concursos de canciones) de Música Nativa/Nativista extendidos en toda la región. En la década de 1980, la gran respuesta social a dichos festivales entre los grupos de la clase media urbana blanca colocó a la creación musical como una cuestión crucial para debatir temas de conservación/pérdida de tradiciones versus la innovación/transformación de una identidad regional dentro de la englobadora sociedad brasileña. Los festivales de Música Nativa funcionaban como una arena de confrontación para los cantantes, compositores e instrumentistas de todo el estado de Río Grande do Sul; situaban codo a codo a creadores con diferentes orígenes musicales, procedentes de distintas culturas microrregionales. En consecuencia, el sistema

\footnotetext{
${ }^{3}$ He analizado extensamente estos movimientos históricos que se centran en la figura mítica del gaucho-peón, que surgió entre los intelectuales locales en el cambio de los siglos XIX y XX, así como sus implicaciones en la construcción de una identidad nacional en Lucas, 1990.
}

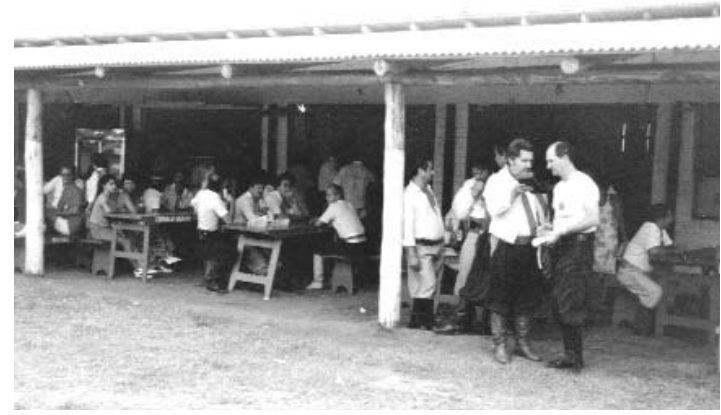

Momentos de socialización en el campamento del festival.

normativo de estos festivales propició la confrontación entre concepciones distintas de autenticidad y experiencia en la creación y ejecución de géneros locales de canciones. Por otra parte, movilizaban a un gran público que iba de 2000 a 15000 participantes por día y hasta 100000 personas por festival. En la década de 1990, el promedio de estos eventos era de aproximadamente cuarenta o cincuenta al año extendidos por todo el estado; el modelo se exportó a los estados vecinos de Santa Catarina y Paraná, donde hay comunidades de gauchos migrantes. El perfil social de estos participantes puede describirse como citadinos blancos de la clase media de las ciudades del interior de Río Grande do Sul, asociados sobre todo con el sector de servicios y pequeños comercios rurales/urbanos. Por medio de su participación en estos festivales exhiben lo mejor de su orgullo local y su vínculo con las tradiciones rurales gauchas.

Los signos de "gauchería" aparecen asociados con escuchar música gaudéria [es decir, música ranchera, rústica], vestir como gauchos, beber té de yerba mate, preparar asados, bailar y cantar en los campamentos del festival. ${ }^{4}$

\footnotetext{
${ }^{4}$ El marco de la competencia ayuda a llenar el vacío entre la imaginación y la experiencia sociales. Los campamentos del festival (apodados ciudades de lona) simulan un ambiente urbano con calles, alcaldía, instalaciones médicas, bancos y tiendas de abarrotes; propician la representación de la vida pastoril dentro de condiciones modernas de esparcimiento. Vestidos de gaucho-peones con pantalones holgados con bordados laterales (bombachas), botas y cinturón de cuero, pañoleta y sombrero, cientos de personas circulan en estos espacios con sus jarros de yerba mate (cuias), asisten a asados y tandas de música durante los tres o cuatro días de los concursos. La exteriorización de la gauchería mediante estos emblemas populares (que son rechazados
} 
En suma, los festivales estimulan la imaginación social en torno al topoi de la "madre patria" en el sentido tan extensamente analizado en la literatura de las "tradiciones inventadas" inauguradas por Terence Ranger y Eric Hobsbawn a principios de la década de 1980.

El evento que enfoca este artículo -el festival Musicanto Sul Americano de Nativismo - fue creado en 1983 por uno de los íconos de la música nativista: el autor de canciones, acordeonista y guitarrista, Luiz Carlos Borges. El festival se instituyó en Santa Rosa, una ciudad agrocomercial situada en la frontera noroeste entre RS y Argentina. Desde el principio, entre los músicos y asistentes, este festival estableció una reputación como el concurso para los mejores compositores de música nativista. Su mentor tuvo especial cuidado en promover el evento, seleccionando al jurado y ofreciendo una buena infraestructura para las presentaciones. Al inicio algunos de sus pares dudaban que un festival nativista pudiera tener éxito en una ciudad dominada por una población de descendientes de inmigrantes alemanes, que ellos pensaban carecían del "estilo gaucho" de las rancherías tradicionales de la pampa, tales como Uruguaiana, el lugar de nacimiento de la matriz de todos los festivales nativistas, la Califórnia da Canção Nativa, celebrada por primera vez en 1971.

A pesar de este "problema de identidad", el festival fue exitoso en su primer año y no dejó de crecer. Quizá una de las razones de este éxito fue el hecho de que la población de Santa Rosa tenía una sólida situación económica alcanzada mediante el agrocomercio de frijoles de soya. Esto permitió a las autoridades de la ciudad promover palmariamente un "proyecto nativista" como su contribución para enriquecer la escena cultural de RS. Además, los premios en efectivo eran más altos que en otros festivales; el primer premio era un automóvil nuevo ofrecido por un comerciante de la localidad.

por la clase media urbana de la capital del estado como muestras de origen rural, grosería o vulgaridad) trae a la mente lo que Bourdieu (1980: 69-70) define como la revuelta del estigma mediante su uso; un cimiento social, económico y simbólico que aporta cohesión y movilización al grupo estigmatizado.

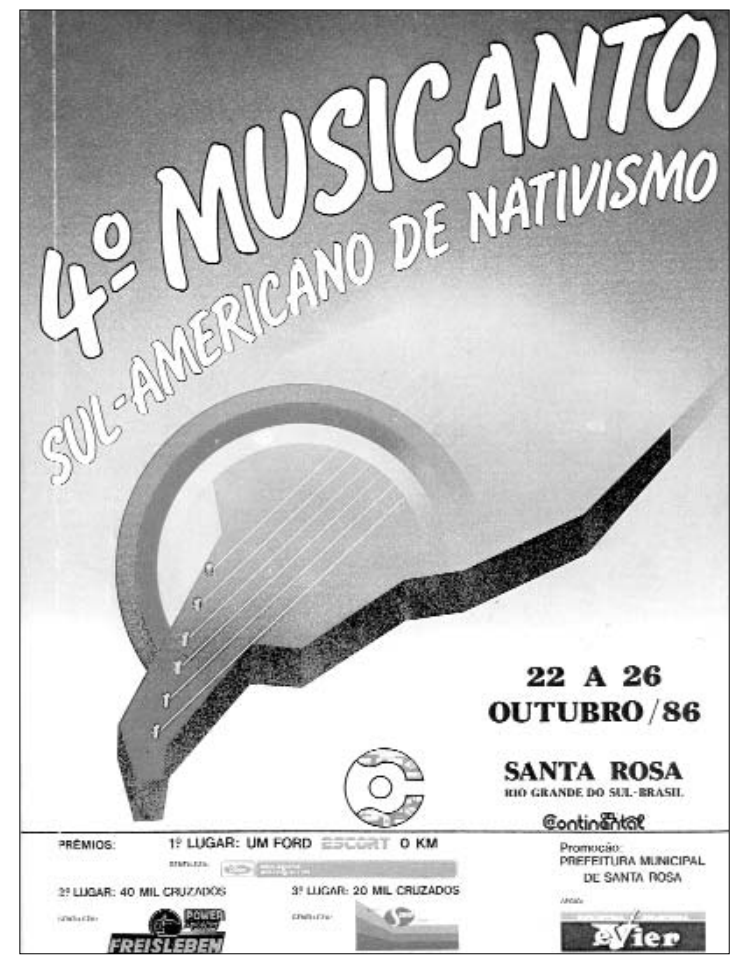

Cartel del festival de Musicanto, celebrado en octubre de 1986.

Pero la alta reputación de Musicanto no radicaba sólo en sus buenas condiciones económicas; también se debía al prestigio personal del que gozaba su figura mentora (Borges) entre sus colegas y admiradores como un músico sobresaliente, bien versado en los géneros y ritmos musicales tanto de RS como del área de Río de la Plata. Sus actuaciones con distinguidos músicos tales como el acordeonista brasileño Sivuca o la cantante argentina Mercedes Sosa, a quien trajo por primera vez a Brasil para dar un concierto que reunió a 10000 personas en el Musicanto de 1984, ayudó a conformar la imagen de Musicanto como un evento que pugna por la alta calidad musical.

Como otros festivales nativistas, las normas de Musicanto se centraban en "el incentivo del arte nativista de RS”. Esto puede apreciarse, por ejemplo, en los objetivos establecidos para el evento: "la proyección de la música nativista de RS a Brasil y Sudamérica, incluyendo desde aquellas expresiones que tienen su origen histórico en lo pastoril hasta la etapa contemporánea de expresión y dinámica social que se está alcanzando mediante el espíritu 




de la creación libre de nuestros artistas" (Regulamento, $4^{\circ}$ Musicanto, Santa Rosa, 1986, art. 2, ítem); así como en las normas establecidas para la composición de canciones: "la creación e interpretación de las canciones concursantes deben obedecer los ritmos tradicionales de RS..." (Ibidem, art. 17).

No obstante, lo estricto de estas reglas era relativo. En la práctica, el giro hacia la apertura o la tradición se volvió más bien una función del perfil del jurado que, en el caso de Musicanto, Borges era responsable de asignar. La mezcla de "progresistas" y "conservadores" se afirmó claramente en la composición del jurado de 1986. Fueron escogidos entre músicos y líricos con posiciones bien definidas en la escena cultural regional de modo que cualquier acusación de prejuicio pudiera desecharse.

Todos estos factores contribuyeron a que poco a poco Musicanto se alejara de los patrones ordinarios de otros festivales nativistas. Por consiguiente, Musicanto se volvió una arena cargada para debatir sobre la tradición versus la innovación en la creación musical. Recibió simultánea- mente apoyo y ataques de los seguidores del movimiento nativista especialmente a través de los medios (artículos en los periódicos, entrevistas, encuestas, transmisiones radiales de los festivales). Un caso específico de esto puede apreciarse en el discurso de los participantes. En cada festival particular tuve la oportunidad de observar la predominancia de ciertos temas que a lo largo del evento eran materia de comentarios, críticas y polémica. En el caso de Musicanto 1986, los temas predilectos eran el carácter experimental de las canciones y lo poco adecuadas que resultaban para un festival que contenía la palabra nativismo en su denominación oficial.

Se escuchaban fuertes críticas y había resistencia a aceptar nuevos proyectos musicales por parte del público reunido en el campamento y en el teatro del centro en el cual tuvo lugar el concurso. En el área del parque donde se levantaron cerca de 400 carpas, tuve la oportunidad de circular entre pequeños grupos de campistas para hablar sobre su participación en el $4^{\circ}$ Musicanto. Los asistentes al festival constantemente expresaron su descontento con el distanciamiento entre el festival y el nativismo y por consiguiente, con su público. La apertura del concurso a lo que los participantes llamaban "música urbana" se consideraba una señal de la debilidad musical del festival y una de las causas de su falta de interés a seguir el concurso. Más aún, su insatisfacción y frustración respecto a la música se intercalaba con amargas quejas sobre la "discriminación social" (su propio término) impuesta por el costo de los boletos para el concurso y el campamento. Dado que estos argumentos se juntaron en sus conversaciones, era bastante fácil percibir que al fin y al cabo estas consideraciones expresaban la protesta de los participantes porque sus intereses y gustos musicales no contaban puesto que no eran parte de la elite social de la ciudad que manejaba el festival. Como dijo un joven que se identificó como empleado de banco:

... hay un tipo de "apartheid" en Musicanto; nos sentimos discriminados porque no nos alcanza para pagar los boletos ni podemos oír las canciones en el campamento. Dijeron [los organizadores] que las canciones se presentarían aquí también, pero no fue así. No creo que les interesa presentarlas aquí. No lo necesitan [los organizadores]. No les interesa mostrar las canciones en el campamento; lo que 
realmente quieren es vender el álbum de Musicanto fuera de RS. En suma, hay dos festivales: aquel del Centro Cívico para las autoridades, la elite de la ciudad, los visitantes de fuera, y aquel del campamento para nosotros los demás.

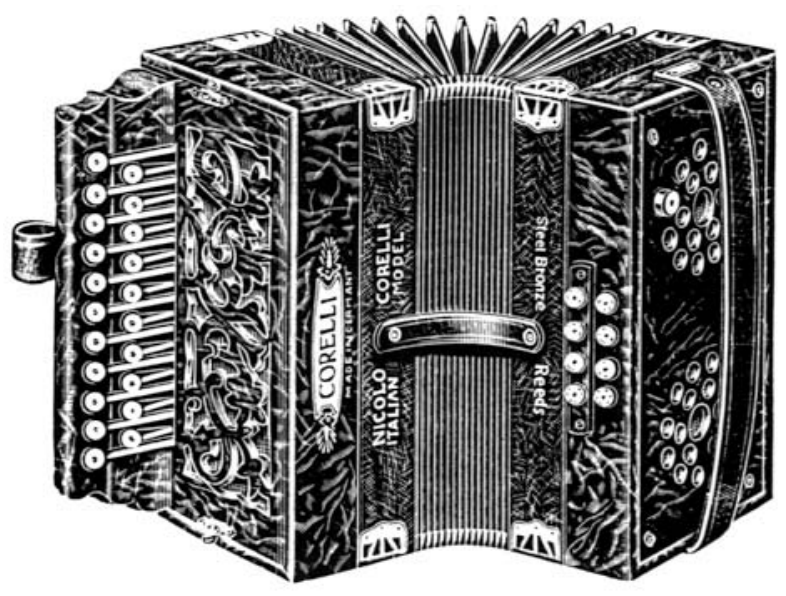

Otro hombre, empleado del Ayuntamiento, quien acampaba con su familia y amigos, expresó inquietudes simipersonas, en el cual algunos participaron en la conversación reforzando el punto de vista de los otros, pero dejemos que esta persona tome la delantera:

Las canciones compuestas para este festival no tienen al público en mente. Falta una definición del concurso. Me gustaría ver al jurado y al comité expresar claramente qué tipo de música es apropiado para el concurso, porque están dejando de lado a la verdadera música nativista. He venido aquí cada año siguiendo al festival. ¡El primer $\mathrm{Mu}$ sicanto fue el mejor! El tercero empezó a distanciarse del nativismo y del povão [las masas, la gente no elite]. Ahora las canciones son más "urbanas" y tienen muchos arreglos. ¡Es puro arreglo! Aquellos que no siguen eso, no tienen ninguna oportunidad. ¿Supiste del Grupo Americanto? Es un grupo nativista de Santa Rosa muy bueno. No lo seleccionaron para las finales. Es una vergüenza. Hoy en día, para que un músico participe en Musicanto tiene que producir "arreglos vistosos" y traer una pila [um monte] de instrumentos al escenario.

En el bar del campamento, una suerte de punto de encuentro entre los campistas y los "curiosos" (los visitantes), conocí a un estudiante de preparatoria quien ahondó

en la "ambigüedad" que se ha establecido entre la etiqueta nativismo y el actual concurso musical de la siguiente manera:

Debería desaparecer la palabra nativismo del nombre oficial de Musicanto, porque las canciones seleccionadas para el concurso no tienen nada que ver con el nativismo. Hasta creo que vale la pena tener esta apertura. No estoy en contra de la "música urbana", pero hace falta definir el festival. Puedo entender esta apertura a las nuevas propuestas musicales [novas propostas musicais], pero a la gente de Santa Rosa no le importa eso. Creo que los festivales dedicados a la música xucra deberían continuar para que no se pierdan los cantores de RS. Si los festivales se concentran sólo en la renovación, la gente olvidará al cantor [tradicional].

Desde la perspectiva del público del Centro Cívico también habían sentimientos encontrados respecto al concurso de canciones. Este público era pequeño (cerca de 500 personas) y se componía básicamente de las familias y amigos de los músicos, representantes de los medios, incluyendo críticos de música de São Paulo y Río de Janeiro invitados a observar el evento, habitantes de Santa Rosa vinculados con la organización —el alcalde, representantes del Ayuntamiento, patrocinadores comerciales, y sus familiares.

El alto costo del boleto era muy selectivo (17 dólares por cuatro noches). Las diferencias sociales entre los miembros del público podían detectarse por la exhibición de costosos trajes formales, que mucho contrastaban con los atuendos gauchos de otros participantes. Su presencia parecía confirmar las divisiones sociales expresadas en el comentario de uno de los campistas que habló de la existencia de "dos Musicantos" - "que la gente en el Centro Cívico está más interesada en ser vista que en escuchar la música".

Sin embargo, no sería justo extender este comentario a todos los participantes. Durante el intermedio la gente circulaba en el pequeño vestíbulo para conocer a los concursantes e intercambiar sus impresiones. Fue en una de estas ocasiones que registré el siguiente comentario de una maestra de preparatoria de Santa Rosa, de 43 años:

Por desgracia, este año Musicanto aún no ha llenado nuestras expectativas. Vinimos a ver un espectáculo si no me- 
jor, al menos de la misma calidad que los anteriores. Yo te pregunto: ¿dónde están los acordeones?, ¿dónde están nuestros atuendos tradicionales y todo lo demás que define al hombre gaucho? Nuestros artistas cambiaron completamente, y no me gustó este cambio. Espero que Musicanto siga siendo lo que era o bien que al menos reciba inmediatamente una definición al sacar el término nativismo.

La reacción de esta maestra se confirmó con la conducta del público durante la noche previa a las finales. Aquellas canciones más tradicionales — las gauchinhas - se recibieron con mayor entusiasmo. De hecho, el voto del público para la canción más popular terminó siendo para "Os Filhos de Don José" ("Los hijos de don José"), cuya letra alude a la unión entre los brasileños y los hispanos que vivían en las tierras de la frontera sur. Si bien el jurado no la incluyó entre las doce finalistas, recibió la preferencia del público por dos razones: a) era una canción nativista tradicional, tocada sólo con instrumentos acústicos (acordeón, guitarra, bombo); b) la interpretó el Grupo Americanto, oriundo de Santa Rosa.

A diferencia de los miembros del público que manifestaron su descontento por el carácter menos tradicional de las canciones y no parecían motivados a seguir el concurso, sobre todo en el campamento, el grupo de músicos y autores de canciones en general estaban contentos con la oportunidad de escuchar cosas nuevas.

A pesar de la retórica regionalista de sus reglas, $\mathrm{Mu}$ sicanto estaba viviendo una etapa de transición en términos del perfil de sus concursantes. En 1986 atrajo a un grupo heterogéneo de músicos en términos de carrera, destreza musical y capital cultural. Se veía que para el grupo de compositores el festival se volvió un punto de encuentro para intercambiar o recoger ideas para canciones futuras y para debatir sus posturas sobre la estética de la canción. Toda la atención se centraba en seguir la presentación de las canciones en competencia (o rivales), en los comentarios del intermedio y en las críticas del trabajo de unos y otros. De hecho, el grupo de concursantes no mostró mucho interés en hablar con los de afuera, excepto en las entrevistas con las estaciones de radio y periódicos locales. Sus conversaciones denotaban que había una clara disputa en el grupo para establecer ideas hegemónicas sobre la creación artística que no im- portaba discutir con los de afuera. El festival era, de hecho, un campo de poder para que los músicos usaran su capital simbólico para acrecentar su prestigio dentro del concurso y dentro del grupo al que cada quien pertenecía.

Dado que el proceso de preselección favoreció a aquellas canciones no tan ligadas a los ideales regionales de otros festivales, tomó por sorpresa a algunos compositores quienes durante el concurso se dieron cuenta de que eran una minoría. Como oí decir a un miembro del jurado, el número de gauchinhas había disminuido ese año. De 320 canciones enviadas al proceso de preselección, sólo 60 estaban en esa categoría. Las 32 canciones seleccionadas incluían sólo nueve canciones nativistas tradicionales. Este hecho causó cierta protesta y contraataques entre el grupo de concursantes, lo que finalmente indica sus concepciones diferentes respecto a la creación de canciones.

El muy respetado poeta y compositor de canciones regionalistas Aparício da Silva Rillo, cuya canción concursante estaba del lado de la tradición, fue una de las personas que se manifestó en contra del carácter experimental de Musicanto 1986:

Los músicos experimentales se están apoderando del festival; se olvidan de que hay un público allí y me parece que están más preocupados por sí mismos: componen para ellos mismos. La experimentación es válida, pero estos tipos deberían empezar con algo identificable con RS y luego extender su creatividad, si no el público se quedará - $\mathrm{y}$ de hecho se queda-fuera del juego. Si Musicanto va a ser un festival para experimentos [musicales], entonces debería sacar "nativismo" de su título para que no confunda a la gente. (Entrevista, Musicanto, 1986).

Representando el contra argumento, el compositor y poeta Sérgio Napp, quien es un ganador veterano de los festivales nativistas y quien también competía en el $4^{\circ}$ Musicanto, declaró a una estación de radio local durante la transmisión del festival:

No podemos andar echándole piedras a Musicanto. Hay que esperar y acostumbrarse a la idea de innovación. El festival va en el camino correcto. Algunas personas no interpretan el nativismo correctamente: se está confundiendo con el tradicionalismo. Lo nativo es lo que surge del artista, independientemente del género o la forma. La invención 
musical, instrumental y poética no tiene fronteras... Ya hice muchas canciones tales como "Esse Gaiteiro" ["Este acordeonista"], "Baile de Candieiro" ["Baile a luz de vela"] en las cuales aparece el acordeón y los rasgos musicales de RS. Pero a veces tocamos otras formas musicales, y eso no significa que no sean nativas. Esto es Musicanto: es diferente de los otros 50 festivales que se celebran cada año en nuestro estado, porque nos ofrece esta apertura para intentar cosas nuevas.

El discurso "nativo" expresado arriba por un conjunto variado de personas con distinto capital sociocultural es importante para dar fe de cómo los ideales estéticos expuestos en el discurso de los participantes responde a distintos niveles de interés respecto a hacer música. El grupo de productores de canciones y músicos, que se autoidentifican como "urbanos" o "experimentalistas", valoran su progreso técnico y la ampliación de su experiencia musical como una manera de construir una carrera profesional; sus oponentes persisten en el tema de la conservación musical mediante la reproducción de los modelos musicales consagrados por la corriente princien un discurso musical sus posturas ideológicas respecto a la cultura regional.

Por otra parte, el público en general quería gratificarse con las experiencias sonoras que dentro del marco del festival no chocaran con su apreciación de la cultura gaucha tradicional. Se identificaban con lo que ya se había incorporado como música "auténtica" por medio de su exposición a otros eventos similares, mediante la difusión en los medios masivos de comunicación y el proceso de socialización.

\section{LA CREACIÓN DE "BRASILHANA”}

La canción "Brasilhana" puede interpretarse como una concesión con polos estéticos opuestos, como veremos más adelante. Presentada en la primera noche del festival, desde el inicio la prensa y el grupo de compositores la consideró como la probable canción ganadora. La sensación de que ésta era una candidata fuerte al primer premio se confirmó al final de la tercera noche del con-

curso cuando todas las canciones participantes se habían presentado y ninguna de ellas parecía haber igualado el atractivo de "Brasilhana”. Talo Pereyra, un músico argentino que ha vivido en Río Grande do Sul por más de una década, compuso la canción junto con el poeta y periodista Robson Barenho, oriundo de RS. Las fuerzas de representación en el escenario reunieron a un artista emblemático de los festivales nativistas, el cantante Neto Fagundes, acompañado de cuatro percusionistas, un bandoneonista, un saxofonista, un flautista y el mismo compositor en la guitarra Ovation.

Los compañeros compositores presentes en el festival definieron "Brasilhana" como una grande sacada, es decir, una idea que es bastante simple, que funciona muy bien, pero que nadie había pensado antes. La curiosa mezcla de los ritmos de la samba con la milonga, y la combinación de los timbres correspondientes a la mezcla musical afro-brasileña-hispana (percusión + guitarra + bandoneón) destacaban como los elementos sugerentes de la canción.

En su primera presentación en Musicanto, "Brasilhana" fue anunciada por los anfitriones como una milonga $a^{5}$ brasileira e castelhana, "una expresión de la democracia cultural y musical en las zonas fronterizas del sur de Brasil y Argentina”. En el escenario, una parafernalia instrumental que consistía en "una mini escuela de samba" —pandeiro [pandero], cuíca [tambor de fricción], surdo [tambor bajo], apitos [silbatos], guitarra, bandoneón e instrumentos de viento (flauta, saxofón) — indicaba el entrelazamiento de las tradiciones musicales africanas, brasileñas e hispanas. Combinado con el vestuario de los intérpretes - una mezcla del atuendo gaucho "cool" (camiseta con pantalón abombachado y alpargatas) y el transnacional (jeans y camisetas) — enmarcaron el ánimo festivo/carnavalesco de la canción. La ejecución fuerte-

\footnotetext{
5 La milonga es un tipo de música que se canta o se recita o ambos, no se baila; llegó al sur de Brasil a finales del siglo XIX. Combina la tradición del trovador (payada) de la zona del Río de la Plata con una figura grave de ostinato sincopado que deriva del ritmo habanero. Se interpreta con dos o tres guitarras: una toca la figura ostinato sincopado mientras que el(los) otro(s) puntean. Siempre es en modo menor, generalmente $\mathrm{E}$ menor o $\mathrm{D}$ menor. Se le considera el género musical más emblemático de los festivales musicales nativistas.
} 
mente rítmica, las síncopas rítmicas de la samba de carnaval brasileño, del tango argentino, así como los ritmos cruzados de las percusiones afroamericanas, además de un estilo vocal que es indicativo del canto regional (tal como los patrones de la guitarra en la milonga pampea$n a)$, hacían un paralelo con la temática de la letra. Al final de la presentación, la canción recibió fuertes aplausos y ovaciones del público.

De hecho, la tendencia del público fue mencionar el ritmo y la interpretación del cantante con el conjunto como sus puntos de identidad con la canción. Su familiaridad con el cantante y su estilo vocal —el acento marcado de la zona fronteriza (una mezcla del portugués con los patrones de entonación del español que se habla en la frontera RS-Argentina), el uso de su plena intensidad vocal (un estilo vocal masculino local)—6 parecen haber facilitado la recepción en vivo de la canción. La letra o el tema en sí no se comentaron. Quizá la naturaleza poética de la letra fue responsable de ello. No contenía una narrativa pura centrada en torno a un personaje heroico o a una situación cotidiana de color local, como sucede en muchas letras de canciones nativistas, más bien se estructuraba en torno a imágenes poéticas (véase el texto más abajo). La única referencia al tema directa y fácil de seguir aparece en la segunda estrofa —una comparación entre la mezcla de los idiomas brasileño y español con el carnaval. No obstante, la combinación rítmica e instrumental, al parecer, era más notoria para los receptores debido a los vínculos indicativos e icónicos de bien conocidas expresiones musicales nacionales y regionales, como se mencionó con anterioridad.

De hecho, el "discurso de la canción" destaca su arreglo instrumental y rítmico porque el autor empleó medios muy económicos para ponerle música al texto — dos periodos musicales y cuatro estrofas con versos cortos que se cantan dos veces en el mismo orden. El esquema armónico a lo largo de la canción se sostiene por acordes tónicos/dominantes $\left(\mathrm{Fm} / \mathrm{C}_{7}\right)$ con la excepción del estri-

${ }^{6}$ Este estilo de cantar está marcado por la tensión e intensidad vocales y se reconoce émicamante como derivación de los lazos desarrollados entre los hombres y la vida pastoril de la región de la pampa. billo. Por ende, se expone a la audiencia cinco veces al mismo interludio instrumental (con pequeñas variaciones cada vez) y dos veces a cada combinación tonadatexto. La distinción de los interludios instrumentales se demostró con las intensas respuestas de la audiencia a su ánimo carnavalesco al silbar, aplaudir y bailar en estas partes, más que en el mismo estribillo.

La repetición de la misma tonada por el cantante fue entonces contrarrestada por variaciones en la combinación de timbres musicales y algunos marcadores rítmicos característicos de la samba de carnaval (chiflidos sincopados, "ronquidos" de la cuíca, "repiques") incorporados a la canción durante las presentaciones en vivo del concurso. Como explica Bauman, "cada presentación tendrá un aspecto único y espontáneo, dependiendo de las distintas circunstancias en juego" (1991: 4). Por ejemplo: en la primera presentación de "Brasilhana" los patrones rítmicos de la cuíca podían escucharse más consistentemente a lo largo de la canción. En la segunda presentación, sin embargo, las interjecciones de los instrumentos melódicos —flauta, saxofón y bandoneón- eran más dominantes y más sincopadas, si bien el conjunto de percusiones aún mantenía la fuerza rítmica de la canción (escúchese el extracto musical de esta interpretación de la estrofa 3 + estribillo + interludio final/coda). ${ }^{7}$ Además, una comparación entre las dos presentaciones generales durante el concurso muestra que la primera tendía a ser más "brasileña", en tanto la segunda era más afrohispana debido a que las improvisaciones del saxofón y los tambores eran más del tipo afrocaribeño. Todos estos matices reiteran el carácter espontáneo, no rígido, de las presentaciones musicales.

Por otra parte, a pesar de los claros signos indicativos/ icónicos a nivel sonoro, el marcaje de palabras entre el texto y la música no fue explorado prominentemente. Una excepción es la palabra "carnaval" en el último verso de la estrofa 2; después de pronunciarla se escucha un silbido de carnaval muy agudo con las figuras rítmicas sincopadas usadas en los conjuntos instrumentales de

\footnotetext{
${ }^{7}$ El ejemplo musical reproducido aquí fue grabado durante Musicanto 1986 con el amable permiso de los organizadores del festival.
} 
las escuelas de samba. La palabra "democracia”, que es la última que pronuncia el cantante (y una suerte de manifiesto político del autor de la canción, un célebre periodista y activista político) también fue marcada musicalmente. Obviamente no se trata de un caso de marcaje de palabra, sino de marcaje musical por medio de la disonancia armónica (una segunda menor agregada al tónico en posición raíz), y la prolongación de la última sílaba (sobre una nota sostenida).

Una vez que concluyó el festival, el autor explicó cómo concibió la canción y cómo veía su contribución al movimiento nativista. Su testimonio ilustra la interacción entre la intencionalidad (agencia), la cultura y la sociedad (restricciones estructurales) en la hechura de un artefacto musical ${ }^{8}$ que busca negociar múltiples identidades en un contexto en el que esto no era la regla de interacción, como veremos abajo. Una vez más, sus comentarios ilustran claramente la fricción social introducida en la producción/recepción de las canciones nativistas de los festivales:
Es irónico que fuera un castelhano [castellano, empleado como sinónimo de hispano] el que trajera la samba brasileña al centro de la atención [botar ele na roda] en Musicanto. "Brasilhana" se llamaba originalmente "Brasileira e Castelhana”, pero dado que queríamos transmitir la idea de una síntesis, la integración de una manifestación musical latinoamericana tal como la milonga con la samba brasileña, la resumimos [en el título]...

Creo que necesitamos establecer un punto de contacto entre nuestro regionalismo y el elemento [nacional] brasileño. Tenemos que luchar contra esta ideología que se ha

\footnotetext{
${ }^{8}$ Agencia es un tema esencial en la teoría social contemporánea porque indaga los vínculos entre la acción social individual y colectiva, las formas en que el poder y el significado son negociados por agentes sociales en sus escenarios estructurales (como estudian, por ejemplo, los pensadores sociales tales como A. Giddens, P. Bourdieu, Jean y John Comaroff). Lo traemos a colación aquí para recordar el carácter dinámico de la elección y acción humanas introducidas en la manera en que los intérpretes musicales toman decisiones, cambian de postura y se colocan en la interpretación de la vida social al hacer música. En otras palabras, procesos que implican la intervención cultural de los creadores de música en vez de aquélla de la estructura social por sí sola implicada en las nociones de macrodeterminación de la industria de la música, o las políticas gubernamentales en la producción/ consumo musical.
}

apoderado de RS y que es xenófoba, racista, separatista y sectaria. RS, a pesar de sus particularidades históricas y a pesar de ser un estado fronterizo, es Brasil. Cuando en $\mathrm{Mu}$ sicanto se escuchó el rugido de la cuíca [tambor de fricción], cuando el surdo [tambor bajo] y el pandeiro [pandero] entraron a escena, el festival en verdad terminó porque "Brasilhana” se impuso. Y se impuso porque es brasileña y también gaucha, es decir, que es brasileña y castellana.

"Brasilhana" nació de la fusión de muchos elementos que he aprendido en todos los años que he vivido aquí. Ivaldo me dio la armonía y el carnaval; João Palmeiro y Toneco me introdujeron al jazz. A eso yo agregué lo que me traje de Argentina y luego produje "Brasilhana".

La idea tras todo eso, si es que la hay, es que nuestra música gaucha es un callejón sin salida. Es un arte que está dirigido y sujeto a un sistema normativo. Es necesario inventar, atreverse, pero el artista no está recibiendo esa libertad de despegar y volar. Ésta es la misión del artista. Cuando estoy en el escenario, me escuchan a la vez que yo escucho al público. Nunca estoy seguro de si seré aplaudido o abucheado. Respeto mucho al público. Ellos son los únicos capaces de juzgar una obra de arte, de otorgar o no un premio a la música en un festival. Ésta es mi misión porque toco para la gente. Desde la primera presentación de "Brasilhana" sentí que de alguna manera tocó al público. Cuando estábamos en las finales, la vibración estaba allí con la gente bailando, aplaudiendo y gritando "Já ganhou” (“¡Ya ganó!”). Y “Brasilhana” ganó. (Entrevista con Talo Pereyra, Santa Rosa, RS, 1986.)

\section{COMENTARIOS POSTCONCURSO}

Es importante señalar que la estética musical favorecida en Musicanto generó fuertes reacciones una vez que terminó el festival. La revista nativista Tarca publicó un artículo crítico del festival en el cual el autor definió a Musicanto 1986 como un festival de "calidad musical sobresaliente y escaso nativismo”. Para él, los músicos mostraron un deseo por el cambio musical que los llevó a olvidar los propósitos iniciales del festival, es decir, "ser un festival de arte 'nativo' en vez de una copia de la música estadounidense que se escucha en las estaciones de FM en todo el país" (artículo no firmado, revista Tarca, Porto Alegre, 1986, vol. 3, núm. 16, pp. 20-21).

Siguiendo la misma línea, un lector de la capital del estado vio en Musicanto un festival de rock que ponía en 
MÚsICA: ||: In ter.| A | A | Inter.| A | B : || Coda

TeXTo:||:---| Est.\#1| Est.\#2| -.-|Est.\#3| Estr.:|| -.-

LETRA

\section{Estrofa 1}

Onde vi

Estrelas nuas e haraganas

Quase iguais a ti

Era um rancho

Ou um país, a nossa cama

Nos confins do Chuí

\section{Estrofa 2}

Eram línguas

Brasileira e Castelhana

De sabor igual

Numa festa

Tão bonita e tão profana

Quanto o carnaval

\section{Estrofa 3}

Eram homens

E fuzis violando as rosas

Violentando a luz

Eram menos

Que as manhãs maravilhosas

Que a paixão produz

\section{Estribillo}

Um romance

Estrangeiro e suburbano

Era igual ao dia

Era claro

Como as noites em que amamos,

E a democracia!
Donde vi

Estrellas desnudas y vagabundas

Casi igual a ti

Era (en) un rancho

O un país, nuestra cuna

Nuestros confines de Chuí

Eran lenguas

Brasileña y castellana

De sabor igual

[Sucedió] en un festival

Tan bonito y $\tan$ profano

Como un carnaval

Eran hombres

Y fusiles violando las rosas

Violentando la luz

Eran menos [en comparación con]

Las maravillosas mañanas

Que la pasión produce

\section{Un romance}

Extranjero o suburbano

Era igual al día

Era claro

Como las noches en que amamos

Y [luego] jla democracia! 
riesgo los valores que los "verdaderos" gauchos luchan por mantener vivos. Escribió a un periódico local una petición pidiendo la inmediata intervención del MTG (Movimiento Tradicionalista Gaucho). ${ }^{9}$ Una vez más se emplean las estrategias retóricas del discurso tradicionalista para crear conciencia de la "amenaza a las tradiciones locales" por "fuerzas ajenas".

Para nosotros los tradicionalistas, Musicanto fue una tremenda decepción. Si pensamos en el último Califórnia en Uruguaiana [15 ${ }^{\mathrm{a}}$ Califórnia, 1985] esto no es inusual porque observaremos la presencia de estas infiltraciones cuyo objetivo es desarraigar nuestra cultura. Por desgracia, $\mathrm{Mu}$ sicanto fue genuinamente un festival rockero [um festival roqueiro].

Tenemos que abrir los ojos: tenemos que vigilar nuestra memoria farroupilha. No dejemos que media docena de personas degraden lo que a los gauchos, conscientes del deber farrapo, les tomó años construir.

Hay un rumor de que en el próximo Califórnia habrá un invitado especial para dar un concierto. ¡Este invitado es nada menos que Caetano Veloso! El MTG tiene que hacer algo muy urgentemente; si no, en dos o tres años nuestros festivales van a ser dedicados a los músicos populares brasileños.

El que calla otorga. MTG, el llamado por hacer algo ruge en las gargantas de los verdaderos tradicionalistas. No dejemos que las influencias extranjeras cimbren la estructura y la magia del verdadero tradicionalismo. (E. J. R., Zero Hora, 27 de noviembre, 1986).

Resulta interesante que la amenaza a la cultura local no sólo es de afuera (la música rock), sino también de los músicos brasileños. El texto revive metafóricamente la

${ }^{9}$ El MTG fue creado en 1948 por un grupo de jóvenes estudiantes con la finalidad de cultivar las tradiciones de los gauchos, es decir, aquellos valores y expresiones asociados con la cultura pastoril de la región de la pampa. Llegó a un amplio público de RS gracias a la creación de clubes sociales dedicados a este fin, los así llamados Centros de Tradições Gaúchas (CGT). Hoy en día hay este tipo de centros en todo el país, incluso en el extranjero (Estados Unidos, Japón, Portugal, Bolivia). La dimensión social y el prestigio del MTG, con una afiliación en RS estimada en un millón, sus vínculos con el aparato de Estado mediante el Instituto Gaúcho de Tradição e Folclore (fundado en 1970 por la demanda y presión de MTG) ayudó a establecerlo como una autoridad en materia de cultura e historia regionales; muchos organizadores de festivales nativistas contaron con el apoyo del MTG en la elaboración de su sistema de normas. Para más análisis en este tema véase Oliven, 1996. idea de proteger las fronteras regionales contra la invasión cultural nacional/extranjera. Invocar la memoria "farroupilha” (la revolución separatista de RS que tuvo lugar en 1835-1845) y el deber "farrapo" (la defensa de RS por el pueblo) es sintomático del vínculo simbólico que la imaginación social contemporánea atribuye a la cultura guerrera y a la contienda histórica de RS. El discurso textual y musical de "Brasilhana" buscaba sobreponerse a las fronteras locales musicales así como a los ideales de autenticidad proclamados en el discurso regionalista. Aun apelando a la herencia cultural común del Cono Sur de América mediante la unión de signos musicales y lingüísticos de ambos lados de la frontera, el manifiesto no penetró la experiencia común del "culto a las tradiciones locales" tan predominante en los cuarteles regionalistas de RS en ese entonces. El choque entre la creación de canciones y la recepción de las canciones requiere mayor estudio.

\section{CODIFICACIÓN CULTURALYTRANSCULTURAL DE METACOMENTARIOS DE LAS PRESENTACIONES DE CANCIONES}

La experiencia etnográfica de la producción musical nativista exhibida mediante los festivales de canciones muestra que este repertorio está sujeto a un proceso continuo de mediación de lenguaje entre lo que se escucha y lo que se recibe al escuchar. El hablar o el discutir estos sonidos y formas textuales significa que aquéllos directamente involucrados en hacer música - músicos, cantantes, audiencia, miembros del jurado, críticos de música, medios de comunicación masiva - crean y reproducen un discurso metafórico para clasificar, calificar o descalificar las canciones del festival ya sea en su totalidad o como significantes musicales específicos. Una parte importante del discurso producido y consumido sobre esta música revela la hegemonía de la cultura pastoril gaucha en el efecto lingüísticamente marcado de los metacomentarios musicales. De hecho, podríamos señalar aquí la oposición antropológica clásica entre los reinos de la Naturaleza y la cultura. Los elementos de esta oposición también podrían incluir un paralelo analógico entre el orden social y las concepciones musicales, basadas en las retóricas expresa- 
das en las prácticas discursivas de los grupos en oposición. Del lado de la Naturaleza está: 1) SONIDO ACÚsTiCO. Autenticidad musical $=$ rural, sociedad pastoril $=$ conducta normativa, orden social jerárquico. En contraste, el reino de la cultura está representado por 2) SONIDO DIGITAL. Innovación musical = sociedad urbana moderna $=$ conducta antinormativa, orden social democrático.

Este proceso de transposición metafórica de un reino de la experiencia social a otro aparece claramente a nivel de las categorías émic, empleadas por todas las clases de participantes para hablar de las canciones del festival o de la música regional en general. Dado que hay una clara disputa ideológica entre los participantes para establecer lo que es auténtico/espurio o a la inversa, para alabar la innovación musical sobre el conservadurismo en las canciones concursantes, el resultado es una bipolarización de las concepciones musicales codificadas por una elección lingüística que denota la postura estética del orador. Estos marcadores lingüísticos regionales empleados en el discurso sobre la música ${ }^{10}$ son referentes importantes para entender sus articulaciones sociales dentro y fuera del reino musical. Como señala Michel de Certeau en su análisis sobre la escritura y oralidad en los usos sociales del lenguaje: "la credibilidad del discurso es lo primero que hace a los creyentes actuar de acuerdo con éste. Produce practicantes. Hacer que la gente crea es hacerla actuar” (De Certeau, 1984: 148).

Los datos etnográficos ligados a "Brasilhana” (discursos émic de los compositores, intérpretes, miembros del público, medios de comunicación) lleva la marca de mensajes contradictorios englobados dentro del mismo código sonoro, en este caso una canción que supuestamente mezclaba los signos de los géneros musicales africanos, brasileños e hispanos. Por parte del compositor y los intérpretes de "Brasilhana" hay una intención declarada de

${ }^{10}$ Algunos ejemplos de este campo: música gaudéria = tradicional, auténtica, como el antiguo gaucho; música campeira o $x$ ucra $=$ tradicional, que viene de la gente del campo, los gauchos auténticos; música pampeana = idem ; música de gaitaço = peyorativo, en los festivales se refiere a canciones seudofolclóricas que dependen sobre todo del acompañamiento del acordeón de botones o teclado; gauchinhas = peyorativo, música para bailar o canción seudofolclórica. crear un signo colectivo de identidad para los brasileños e hispanos del área del Río de la Plata. Las relaciones intermusicales llevadas por el discurso musical, los significados interculturales introducidos en el título y texto de la canción (brasileño + castellano), así como la mezcla de intérpretes nativos de la zona del Río de la Plata califican a "Brasilhana misma" como una pieza etnográfica en el sentido de que revela un discurso émic (inscrito en la música, letra e interpretación) sobre el tema de la transculturación en la canción popular y, hay que señalar, mucho antes de que el concepto de "música del mundo" llegara a Brasil.

Acuñado en la década de 1940 por el sociólogo/etnomusicólogo cubano Fernando Ortiz en su libro Contrapunteo cubano del tabaco y el azúcar, la transculturación era una manera de describir el carácter procesal de los intercambios entre la cultura africana y europea en Cuba. En contraste con las nociones más unilaterales, segadas hacia la metrópolis de la aculturación/deculturación, la noción de transculturación de Ortiz hace hincapié en el intercambio cultural, la interacción y la fertilización cruzada, que da como resultado un fenómeno o realidad completamente nueva.

No es casualidad que la transculturación se ha reconsiderado significativamente en el campo de los estudios culturales y postcoloniales. Mary Louise Pratt (1992), por ejemplo, lo refiere como "un fenómeno de la zona de contacto" - aquellos espacios sociales en los cuales "culturas desiguales se encuentran, chocan y luchan entre sí, a menudo en relaciones altamente asimétricas de dominio y subordinación - como el colonialismo, la esclavitud o sus secuelas como se viven en el mundo hoy en día" (1992: 4). En tanto esta línea de pensamiento se enfoca en la naturaleza hegemónica del contacto cultural entre el centro y la periferia, "Brasilhana” añade otra perspectiva a este debate: una relación de red descentralizada entre Europa, África y América. Esta ecuación, expresada mediante la yuxtaposición de una variedad de signos musicales creados bajo el encuentro cultural entre las metrópolis versus las periferias, así como de las periferias versus las periferias, desafía cualquier sistema de clasificación basado en las premisas de rasgos musicales genuinos, puros, auténticos, originales. 
A pesar de toda la intencionalidad, "Brasilhana", no obstante, fue concebida como un signo musical transcultural dentro del campo de un conflicto cultural (las disputas en torno a la tradición y la autenticidad en el regionalismo gaucho). Por ende, del lado de la recepción, el mensaje de transculturación no se aceptó plenamente pues chocaba con el tipo ideal de "música pura auténtica de RS". Como muestran los pasajes citados arriba, este mito alimenta una parte importante de la imaginación social local. La cuestión de la autenticidad en la música nativista está ligada al campo del poder en el cual los "expertos" en regionalismo gaucho (p. ej. folcloristas, poetas, periodistas) y varios músicos, alegando legitimidad y autoridad debido a sus fuertes vínculos con la región microcultural de la pampa (la cuna de la figura mítica del gaucho-peón), han cabildeado históricamente en las instituciones del Estado para imponer su conocimiento y experiencia personales como el modelo más legítimo de representación cultural para toda la región.

La resistencia a la "innovación" o el temor a perder los elementos gauchos tradicionales en su música aparece más abiertamente entre aquellos grupos sociales ligados a canciones que reproducen ciertas fórmulas y géneros musicales, considerados "tradicionales" de acuerdo con el sistema normativo de muchos festivales nativistas. Dicho de otro modo, encontramos reproducido aquí el clásico debate estético centrado en la imitación/reproducción de la tradición versus la creatividad libre. En tanto la estética de "Brasilhana" abiertamente sigue el juego de la transculturación, la diversidad cultural y múltiple identidad, realzando la mezcla de los encuentros musicales entre África, América y Europa, el realismo estético, que gobierna la idea de identidad regional, destruye la diversidad musical local y trata de imponer un protocolo musical homogéneo por medio de una "formación discursiva”: el regionalismo gaucho. Paradójicamente, pensando desde una perspectiva émica, el interculturalismo está en el meollo de los parámetros estilísticos de aquellos géneros musicales que se etiquetan como "música auténtica de Río Grande do Sul”. Las habaneras, polkas, mazurkas, schottisches y valses que llegaron al sur de Brasil en un proceso de transculturación mundial durante el siglo XIX se volvieron las vaneirões, polcas, ranchei- ras, chotís, valsas del regionalismo gaucho y de los festivales de música nativa.

La reflexividad aportada a la práctica de los antropólogos ha demostrado en qué medida las nociones analíticas de pureza en la antropología social, así como en los estudios de folclor y etnomusicología, estaban en deuda con las teorías racial-racistas del siglo XIX. En el renacimiento contemporáneo del regionalismo gaucho en el sur de Brasil, las narrativas del debate sobre los repertorios nativistas en los medios mostraron la extensión de esta línea de pensamiento y el peso del esencialismo en las representaciones de la gauchería. En este contexto "Brasilhana" ejemplifica el surgimiento de fuerzas contra hegemónicas centradas en la agencia del discurso e interpretación musicales así como la contribución de estas prácticas a las experiencias de aprendizaje social sobre el largo plazo. Más allá de la influencia de una expansión expresiva de la industria musical local en los años 1990 (Lucas, 2000), la práctica cultural y la socialización mediante el intercambio de capital musical entre un grupo de músicos heterogéneo, del cual "Brasilhana" es un buen ejemplo, con el tiempo ayudaron a girar y cambiar los significados ligados a la música regional. El actual discurso sobre hacer música tanto como las prácticas sociales de la creación de canciones, la interpretación y el consumo de música regional han relajado el carácter de confrontación de aquellos años en los cuales se concibió "Brasilhana". Por consiguiente, ahora existen versiones menos monolíticas de la cultura e identidad gauchas. La biografía estratificada de "Brasilhana" es testimonio del hecho de que el contexto cambiante y variable de la contestación reitera el carácter provisional de una cultura musical, la continua reinvención de la cultura en el presente.

\section{Bibliografía}

Bauman, Richard, 1991, Story, Performance, and Event: contextual Studies of Oral Narrative, Cambridge University Press, Cambridge.

— 1993, Verbal Art as Performance, Newbury House, Rowley.

Blacking, John, 1983, “The Structure of Musical Discourse: the Problem of Song Text", Yearbook for Traditional Music, núm. 14, pp. 15-23. 
Bourdieu, Pierre, 1980, "L’identité et la représentation: éléments pour une réflexion critique sur l'idée de région", en Actes de la Recherche en Sciences Sociales, pp. 63-72.

- 1990, The Logic of Practice, Stanford University Press, Stanford.

Brackett, David, 1995, Interpreting Popular Music, Cambridge University Press, Cambridge.

Certeau, Michel de, 1984, The Practice of Everyday Life, University of California Press, Berkeley.

Feld, Steven, 1984, "Communication, Music, and Speech about Music", Yearbook for Traditional Music, núm. 16, pp. 1-18.

Giroux, Robert, 1985, "De la methodologie dans l'étude de la chanson populaire", en La Chanson en Question, Triptyque, Montreal.

Hennion, Antoine, 1983, "The Production of Success: an Anti-Musicology of the Pop Song", Popular Music, núm. 3, pp. 159-193.

Lucas, Maria Elizabeth, 1990, Gauchos on Stage: Regionalism, Social Imagination and Tradition in the Festivals of Música Nativa, Rio Grande do Sul, Brazil, tesis doctoral, University of Texas, Austin.

_, 2000, "Gaucho Musical Regionalism", British Journal of Ethnomusicology, vol. 9, núm. 1, pp. 41-60.
Middleton, Richard, 1994, Studying Popular Music, Open University Press, Milton Keynes.

Oliven, Ruben, 1996, Tradition Matters: Modern Gaucho Identity in Brazil, Columbia University Press, Nueva York.

Pratt, Mary Louise, 1992, Imperial Eyes: Travel Writing and Transculturation, Routledge, Londres.

Pickering, Michael y Tony Green (eds.), 1987, Everyday Culture: Popular Song and the Vernacular Milieu, Open University Press, Milton Keynes.

Shepherd, John, 1982, "A Theoretical Model for the Sociomusicological Analysis of Popular Musics", Popular $\mathrm{Mu}$ sic, núm. 2, pp. 145-177.

-, 1991, Music as Social Text, Polity Press, Cambridge.

Stefani, Gino, 1987, Para entender a música, Globo, Río de Janeiro.

Tagg, Philip, 1982, "Analysing Popular Music: Theory, Method and Practice", Popular Music, núm. 2, pp. 37-67.

Tatit, Luiz, 1986, A canção, eficácia e encanto, Atual, São Paulo.

—, 1994, Semiótica da canção: melodia e letra, Escuta, São Paulo.

—_, 1995, O cancionista: composição de canções no Brasil, EDUSP, São Paulo.

Turner, Victor, 1982, "From Ritual to Theatre", Performin Arts Journal, Nueva York. 